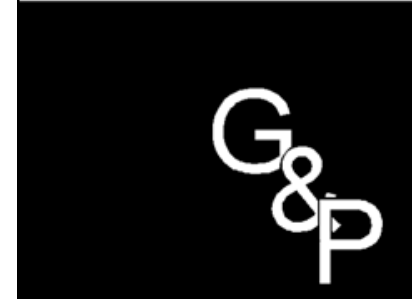

GESTÃO

$\&$

PRODUÇÃO

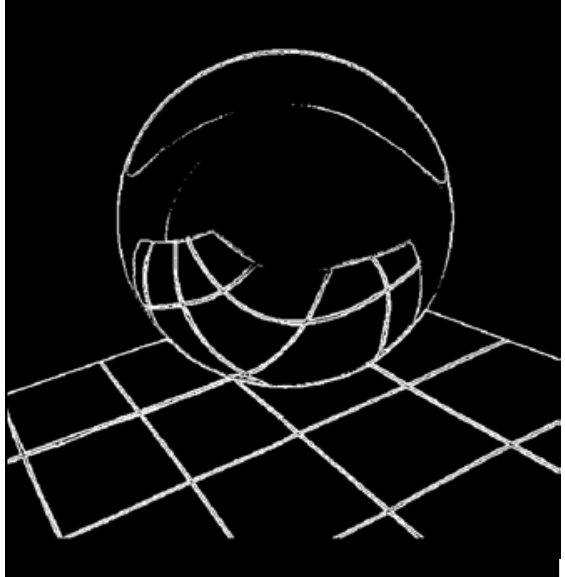

v.6, n.2, p. 127-140, ago. 1999

\section{GESTÃO DE CUSTOS FLORESTAIS: UM ESTUDO DE CASO UTILIZANDO O ACTIVITY-BASED COSTING}

\author{
Alcir Ribeiro Carneiro de Almeida \\ Israel Brunstein \\ Escola Politécnica da Universidade de São Paulo \\ Departamento de Engenharia de Produção \\ Av. Prof. Almeida Prado, 123 - Trav. 2 - Butantã \\ 05.508-900 - São Paulo - SP \\ E-mail: alcirra@usp.br
}

\title{
Resumo
}

No atual cenário de industrialização globalizada, tornou-se fundamental a eficácia no gerenciamento dos custos considerados inevitavelmente necessários. Programas convencionais de redução dos custos não consideram o grau de agregação de valor das atividades de rotina pela distorção dos sistemas contábeis atuais. No presente estudo, apresentam-se os principais motivos da falta de relevância das informações de custo, comenta-se sobre o problema da redução de desperdícios florestais e suas conseqüencias. A partir de um estudo de caso em uma empresa do setor florestal, demonstra-se uma simulação do Activity Based Costing (ABC) em uma determinada área da empresa, concluindo-se que a adoção de sistemas de custeio mais aprimorados, tal como o ABC, devem fazer parte de programas que busquem o aumento da competitividade do setor florestal.

Palavras-chave: gerenciamento de custos, economia florestal, custeio baseado em atividades.

\section{Introdução}

$\mathrm{C}$ omo nos demais setores industriais, o setor florestal também vem sofrendo acirrada concorrência pelo incremento de novos fornecedores mundiais de produtos madeiráveis.
Este setor que possuía concessões protecionistas até a década de setenta, como subsídios e incentivos governamentais que lhes permitiam repassar todos os custos ao cliente, se encontra hoje em um ambiente exigente de eficiência, no fornecimento de novos serviços e de produtos 
com características mais inovadoras. Atualmente, o mercado está exigindo cada vez mais produtos de maior grau de processamento, tais como o MDF (Medium Density Fiberboard), OSB (Oriented Stand Board), LVL (Laminated Veneer Lumber) e demais produtos de madeira, consorciada com outros materiais, como à base de cimento e aço, por exemplo. Esse crescimento de produtos diferenciados necessários ao mercado, aumenta a complexidade da execução do trabalho por toda a indústria, gerando uma das principais causas do acréscimo generalizado dos custos de produção, agravado pela intensa mecanização e automação que alocam os empregados, ainda mais nas funções de apoio, impulsionando os custos indiretos em relação aos diretos.

Antes da abertura do mercado, a maioria dos administradores florestais brasileiros acreditava que a abundância de mão-de-obra barata e intensamente empregada em todo território nacional poderia lhes fornecer uma vantagem competitiva em relação aos concorrentes internacionais (ALMEIDA, 1995). Naquela época, as empresas se preocupavam em repassar as ineficiências e os desperdícios decorrentes para o cliente do processo seguinte, associado a preços mais altos, e menosprezando incentivos para redução dos custos de produção. Todavia, o aspecto da qualificação profissional tornou-se fundamental pelo comprometimento crescente do funcionário com a qualidade e a produtividade dos serviços prestados. Foi-se agravando a problemática gerencial em contestar, com freqüência, os sistemas de custeio, impostos ao pessoal da área técnica pelos profissionais de contabilidade, alheios do conhecimento de campo em processos operacionais que, na atualidade, congregam um mix de produtos e variedades, visando atender aos anseios dos diferentes estágios produtivos inerentes ao setor florestal.

Mediante tantos desafios, os administradores florestais começaram a se voltar para as informações de custo, confrontando os dados da contabilidade, fundamentais para tomada de decisões gerenciais com as suas necessidades de monitorar a evolução em direção às metas estabelecidas, e atentar para situações de investimentos futuros. A geração dos relatórios gerenciais, se dá por meio de demonstrações de resultados operacionais para as chefias departamentais, e de forma sintetizada para a alta administração. Tradicionalmente, mostram valores planejados e reais, e o diferencial entre os dois para o período corrente e anual. Esses relatórios, baseados em demonstrações convencionais, têm dificultado também a compreensão dos executivos florestais em entender a exata composição dos custos de overhead aos produtos e serviços comercializados, além da inabilidade para se elaborar programas eficazes de redução de atividades improdutivas.

Partindo desse pressuposto, verifica-se que os procedimentos contábeis tradicionais de alocação dos custos indiretos se evidenciam inadequados, podendo promover distorções significativas no custo final dos produtos/serviços, por não refletir de maneira ideal a demanda de recursos de cada output individualmente.

\section{O Sistema de Custeio e a Redução de Desperdícios}

Como em muitas outras atividades do cotidiano humano, o processo de trabalho pode estar relacionado a rotinas improdutivas desempenhadas no local de serviço, que compromete muitos dos recursos da empresa, a inadequada utilização de materiais e processos que não resultem em agregação de valor ao produto, e conseqüentemente ao cliente. De acordo com BRUNT (1992), à medida que o tempo passa, surgem rotinas na empresa nas quais não existem a disciplina necessária para promover uma redução significativa dos custos; por isso, torna-se imprescindível analisar criteriosamente cada procedimento, a fim de se buscar novas formas minimizadoras de custo.

Ao se depararem com a necessidade de reduzir custos, muitas empresas respondem com uma diversidade de medidas, que variam desde simples cortes no orçamento até importantes 
programas de racionalização, os quais, se não forem adequadamente planejados e implantados, podem resultar em supressões arbitrárias e precipitadas. Programas de melhorias que visem à redução de custos, quando mal projetados, comprometem a motivação dos empregados na participação destes e de quaisquer outros programas futuros de melhoria da qualidade e produtividade.

Em 1911, TAYLOR (1978) já preconizava a necessidade de se estimar os desperdícios diários oriundos da rotina do trabalho, decorrentes de atividades ineficientes e mal orientadas dos funcionários. Evoluindo este conceito, DRUCKER (1992) descreve que a única forma de redução dos custos é a reestruturação do processo do trabalho, com estabelecimento de metas anuais de incremento da produtividade de cada operação, em torno de três por cento. Acrescenta também que "se tudo que estiver sendo feito se resumir em cortar custos, sem a instalação de um sistema adequado de prevenção de custos, dentro de poucos anos certamente os custos excessivos voltarão". Conforme SLACK (1993), os programas de redução dos custos na grande maioria, se mostram demagógicos em aparentarem uma relevância pontual em determinado segmento, ao invés do mais fundamental, porém menos confortável, exercício de analisar as causas ocultas do custo. Também para este autor, os determinantes estratégicos dos custos são o volume de saída do produto, a variedade de produtos e atividades desempenhadas, e a variação no volume demandado ao longo do tempo.

BERLINER \& BRIMSON (1992) exemplificam a inabilidade no monitoramento dos custos quando mencionam que estudos elaborados pela Força Aérea Americana evidenciaram que 75\% dos programas de redução de custos submetidos aos contratantes direcionavam-se à redução de pessoal, ao invés de torná-los mais produtivos. Mais especificamente, no setor florestal, JOHNSTON, GRAYSON \& BRADLEY (1977) destacam que a silvicultura é considerada uma atividade de trabalho e capital intensivo que, caso haja uma manutenção elevada do custo de mão-de-obra na estrutura dos custos totais, decorrerá um decréscimo da capacidade de competitividade do empreendimento florestal perante outras atividades industriais. Sendo assim, deve ser priorizada a mecanização das atividades silviculturais, minimizando a intensidade de mão-de-obra, para que as empresas se mantenham economicamente viáveis no mercado, não só pela diferenciação, mas sobretudo pela vantagem de custos entre indústrias do mesmo segmento, e se precavendo contra substitutos, caso apareçam. Também BREPOHL (1980) destaca que o custo de mãode-obra florestal tem uma participação no custo total da produção bastante variável, dependendo do tipo de atividade desenvolvida e da capacidade operacional da organização na produção. Tomam-se como exemplos, os custos de exploração florestal não mecanizada e do viveiro de mudas com semeadura via seringas, em que ocorrem a maior participação de pessoal, podendo alcançar até $60 \%$ do custo total. Em outra abordagem, ALMEIDA (1994) caracteriza os desperdícios verificados na atividade florestal que resultam em custos indesejáveis, como demonstra-se na Figura 1.

Grande parte das perdas identificadas pelo autor está ligada direta ou indiretamente à padronização das operações florestais, que caso se suceda de maneira adequada, deverá eliminar as diferentes formas de se produzir o mesmo output, além de servir de registro de aperfeiçoamento dos processos, sem retrocesso da modernização tecnológica. Ratificando, DEVELIN (1995) declara que a solução para a redução de custos está em identificar e desafiar aquilo que as pessoas na empresa realmente fazem, minimizando ou erradicando esforços por meio da ação para melhorar as formas de geração dos produtos ou serviços.

Em outro relato, SHANK \& GOVINDARAJAN (1995), descrevendo um estudo de caso em empresa florestal, referem-se que na perspectiva de minimização de custos em um setor verticalizado, como tem sido a tendência do setor florestal, compreender as implicações de 


\begin{tabular}{|l|l|}
\hline MATERIAL & $\begin{array}{l}\text { Utilização de insumos (sementes, fertilizantes, herbicidas, inseticidas, } \\
\text { etc.) com características não específicas às necessidades e em } \\
\text { quantidades inadequadas por unidade de produto ou de área. }\end{array}$ \\
\hline MÉTODO & $\begin{array}{l}\text { Metodologia de trabalho incompatível ou desatualizada, sem } \\
\text { considerar aspectos ergonômicos, gerando sofisticação demasiada ou } \\
\text { ausência de aprimoramento nos diversos processos produtivos } \\
\text { (semeadura, preparo do solo, plantio, manutenção, exploração e } \\
\text { transporte). }\end{array}$ \\
\hline MÃO-DE-OBRA & $\begin{array}{l}\text { Capacitação inoperante e descontínua, principalmente do operariado } \\
\text { rural, exigindo maior controle operacional ou excesso, acarretando } \\
\text { custos superiores ao necessário. }\end{array}$ \\
\hline MÁQUINA & $\begin{array}{l}\text { Redução da competitividade técnica pela inadequação da quantidade e } \\
\text { qualidade dos equipamentos, ocasionando significativas flutuações nos } \\
\text { custos de produção. }\end{array}$ \\
\hline
\end{tabular}

Figura 1 - Algumas causas de custos indesejáveis no setor florestal.

como a empresa escolhe concorrer, exige que os benefícios conseguidos por novos investimentos tecnológicos sejam condizentes com o posicionamento estratégico adotado pela empresa, principalmente ao se considerar as atividades de corte e transporte de madeira que, por questões de custo de mão-de-obra, foram terceirizadas na maioria das empresas florestais americanas.

\section{Deficiências do Custeio Convencional}

$\mathrm{G}_{\mathrm{n}}^{\mathrm{e}}$ eralmente, a contabilização dos recursos realizada pelas empresas do setor florestal é determinada da mesma maneira que nos outros segmentos industriais, por meio de sistemas convencionais de custeio. Nesses sistemas, os custos de processamentos silviculturais e industriais são alocados aos subprodutos, produtos e serviços, freqüentemente com base nas horas de mão-de-obra direta, e nas horas de equipamentos. Esses procedimentos resultam que os produtos e/ou processos de baixo volume de produção acabam recebendo a mesma carga de custos de seus similares produzidos em escala de produção, isto é, em elevado volume. Por outro lado, a mecanização associada às novas técnicas de produção florestal substituem, cada vez mais, a mão-de-obra direta por despesas indiretas pelo incremento em pessoal de apoio, para desenvolvimento de processos melhorados, além dos custos associados a manutenção, depreciação dos maquinários, seguros, suprimentos e outros, cada vez mais presentes no segmento. Desta forma, aumentam-se os custos indiretos que outrora atingiam baixos índices em relação ao custo do produto final.

Para exemplificar, tem-se o caso da produção de mudas florestais, no qual se sabe que, principalmente nas grandes empresas, há uma produção em larga escala destinada aos plantios comerciais, e também uma produção de reduzido volume de mudas, com a finalidade de se promover ensaios e experimentos, além de espécies nativas para enriquecimento dos plantios comercias e da fauna local. Normalmente essa pequena produção, porém com requintes que exigem um tratamento especial, promove uma proliferação de insumos exclusivos, necessários à sustentabilidade tecnológica, além do visível aumento da assistência técnica durante todo o processo produtivo, responsável pela maturação adequada das mudas.

Em tempos passados, em função da magnitude das despesas indiretas, o rateio utilizado pela sistemática convencional não penalizava de maneira significativa os custos totais, mesmo 
com pequenas diferenciações entre uma variedade reduzida de produtos. Atualmente, essa metodologia compromete processos inteiramente distintos, ocasionando uma parcela de mudas a ficarem subcusteadas, enquanto a maioria da produção torna-se supercusteada pelo rateamento das mudas especiais. Procedimento idêntico é utilizado nas demais atividades, sejam técnicas ou administrativas, visando "simplificar" o processo de alocação de recursos, porque os sistemas originais de contabilização não previam tamanha complexidade e precisão por parte da gerência operacional.

De acordo com SPEIDEL (1966), o cálculo de custos, na época, baseava-se no plano de execução inserido no planejamento anual da empresa florestal, cuja subdivisão deveria abranger os custos de mão-de-obra, de máquinas e de material, além dos custos de terceiros. O gerenciamento, na sua opinião, deveria estimular a administração a reduzir os custos reais e a controlar a eficiência. Segundo JOHNSTON, GRAYSON \& BRADLEY (1977), a contabilidade florestal quando investigada, indica onde é necessário se obter melhorias, caso haja homogeneidade em relação à operacionalidade das atividades florestais. Também pode elucidar a utilização de recursos, de maneira eficiente ou não, e instituir a economicidade da operação e do empreendimento. Já nessa obra, os autores assinalavam sobre cautelas em relação às deduções das informações de custos, quando se referiam especialmente a operações que pudessem gerar uma variedade de produtos por meio do mesmo processo.

Conforme SÁNCHEZ (1985), há uma diferença significativa entre a indústria de base florestal e as demais, devido à inconstância nos rendimentos dos recursos utilizados, por serem dependentes da variável biológica e atmosférica. Dessa forma, são promovidas alterações constantes nos cálculos dos rendimentos operacionais, e por conseguinte, afetado o planejamento financeiro do negócio.

A importância da precisão do sistema de custeio é descrita por OPENSHAW (1980) como fundamental para o planejamento e orçamento florestal, servindo como base para comparações e análise de alternativas de investimentos, necessárias ao gerenciamento operacional dos custos de atividades silviculturais. HELLINGA (1993) relata sobre a importância da empresa utilizar princípios financeiro-contábeis para calcular a rentabilidade, já que dependendo da situação considerada, o investimento florestal pode se apresentar como pouco rentável, em virtude do tradicional custeio das atividades silviculturais, infra-estrutura, e ainda, do aporte de capital em tecnologia avançada, ocasionando um incremento dos custos indiretos e do custo financeiro do empreendimento. O autor também atenta para o fato de se observar que esses custos, apesar de se demonstrarem essenciais no planejamento da empresa verticalizada, nem sempre são considerados na literatura e na prática florestal.

Outra questão relevante surge quando se busca mensurar a eficácia do processo produtivo da empresa florestal. Os sistemas de custeio convencionais, enquanto sistema de informação gerencial, não propicia elementos para mensurar informações sobre refugos, perdas da produtividade no maciço florestal, adubação inadequada, mudas perdidas no processo de produção e expedição, ausência de capacitação profissional, atrasos no transporte, demora em armazenamentos, capina química ineficaz, ressemeios, degradação ambiental e tantos outros prejuízos econômicos comuns ao setor. Simplesmente, costuma-se tolerar margens consideradas aceitáveis pelo bom senso e desprendimento experimental (ao invés de fatos e dados), e apropriá-las na totalização da operação, supercusteando valores de incômoda busca das causas potenciais, devido à aglomeração de diferentes geradores de custo responsáveis pelos desperdícios na manufatura de produtos/serviços florestais. De maneira conservadora, a contabilidade de custos só informa a gerência florestal sobre os resultados dos custos dos processos, esquecendo-se da qualidade, e caso os custos superem o planejado, alerta para a variação 
desfavorável, porém não auxilia na identificação técnica e operacional do que deve ser corrigido. Talvez se elimine um recurso tentando-se minimizar o orçamento, e por outro lado, se prejudique seriamente um procedimento estratégico importante. Similarmente, é o que preconiza a metodologia de custeio da má qualidade, ou mais popularmente conhecida, como custos da qualidade, embora o que se quantifica não é a qualidade, e sim sua ausência, por isso a nomenclatura clássica é preferível.

De maneira simplificada, GANTZEL \& ALLORA (1996) relatam que os métodos tradicionais de custeio têm como principal característica o enfoque no produto, além do fato de que geralmente não utilizam um número significativo de critérios de rateio, menosprezando as relações interdepartamentais das organizações.

\section{Em Busca de Novos Conceitos}

$\mathrm{O}$ procedimentos contábeis presentes, enquanto sistemas de informações gerenciais, não mais atendem às necessidades de empresas que continuamente buscam novos patamares de competitividade e de rentabilidade. A corrida tem sido pela busca de novos sistemas de custeio, ajustados para um ambiente empresarial mais dinâmico e mais competitivo, em termos de mercados e de produtos. Dentre os recentes métodos de custeio destacam-se o Activity Based Costing - ABC e Theory of Constraints - TOC (GOLDRATT, 1992). Enquanto o ABC busca elucidar o "como está se gastando", a Contabilidade dos Ganhos busca responder "se o gasto em questão aumenta os ganhos da empresa". Ambos os métodos ainda carecem de mais aplicações no setor florestal para que se forme um juízo de valor. Nesse trabalho, buscou-se verificar como o $\mathrm{ABC}$ se comportaria em uma empresa do setor florestal.

O ABC visualiza a dinâmica da empresa como a execução de um conjunto de atividades inter-relacionadas. Essas atividades podem ser executadas por homens e/ou máquinas. A execução de um produto ou serviço demanda a execução de uma seqüência de atividades, isto é, os produtos consomem atividades. Em síntese, são as atividades que consomem os recursos da empresa, enquanto os produtos consomem as atividades. Pelo rastreamento dos gastos de uma empresa pode-se monitorar as diversas rotas de consumo dos recursos relacionando-os às atividades. Essa característica de rastreabilidade é que, em última instância, permite analisar a importância de cada atividade para o objetivo do sistema de custeio.

Para o setor florestal, exemplos de atividades poderiam ser: compra de fertilizantes, manutenção de equipamentos, gradagem do solo, derrubada de árvores, etc. Para se atingir o nível de atividade, é necessário estabelecer uma relação hierárquica criteriosa entre os diversos elementos originados pela análise do $\mathrm{ABC}$, de sentido restrito, porém constantes em qualquer empresa florestal. Exemplifica-se na Figura 2 esta relação hierárquica a partir de uma função de nível de agregação maior.

Por que não adotar uma unidade, diferentemente, da escolha por atividade? Por diversas razões. Inicialmente porque o nível de função é abrangente demais para propiciar um acompanhamento preciso, e por outro lado, as operações são normalmente muito detalhadas e, portanto, dispendiosas para efeito de controle. Como pode-se notar, a atividade representa a mediana na hierarquia (inserida a nível tático), e ainda oferece a vantagem de descrever o processo de manufatura de forma comum, tanto ao nível estratégico como ao operacional, pela familiarização por diversos grupos de profissionais na empresa.

A grande estratégia do método $\mathrm{ABC}$ é analisar se as atividades demandadas são realmente necessárias ao negócio, ao invés da decisão decorrente das informações, oriundas dos sistemas convencionais baseados em volume de produção (Volume Based Cost), decidir eliminar o suprimento de recursos em determinado setor (corte de pessoal, redução de ligações telefônicas, cafezinho e demais gastos), por vezes, 


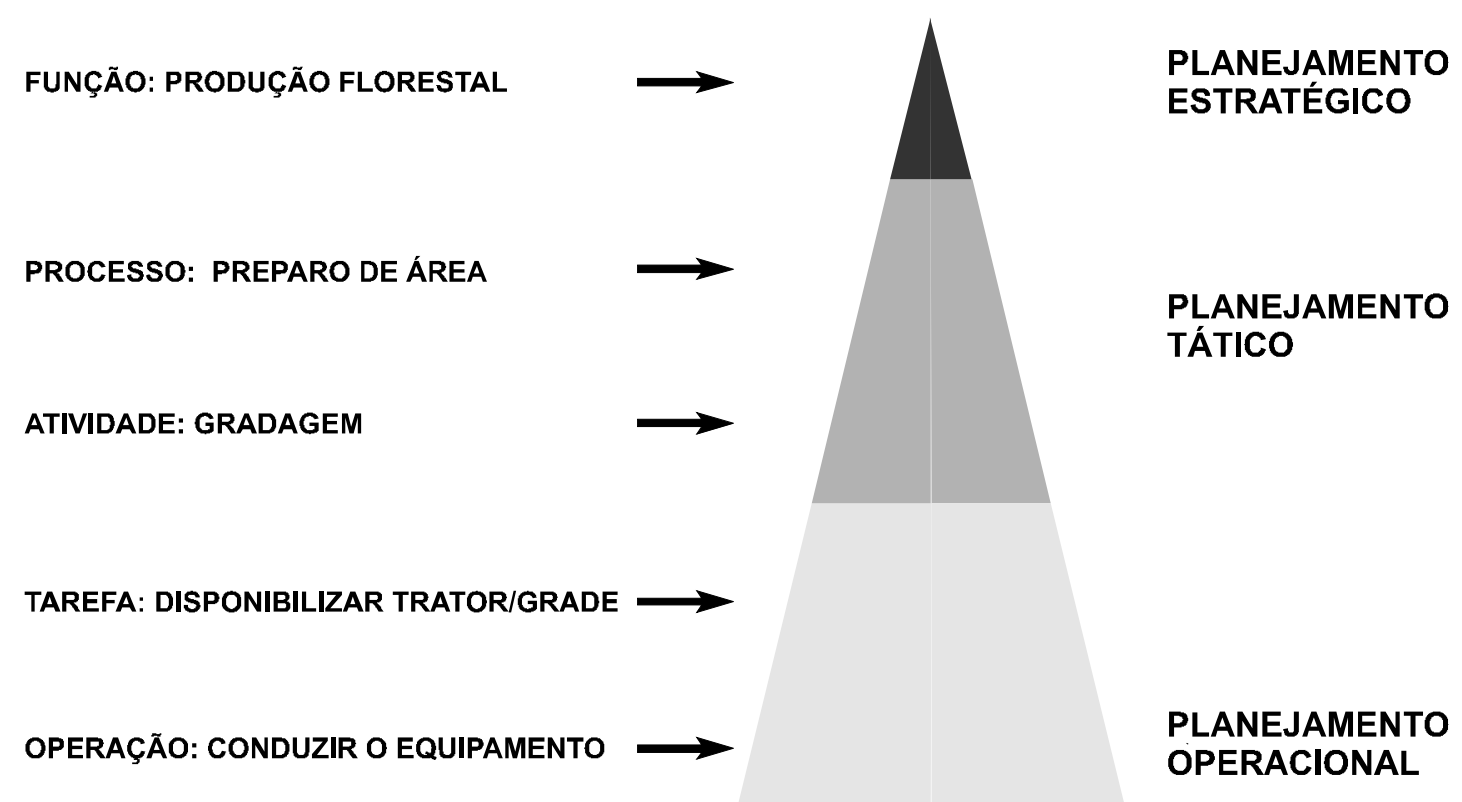

Figura 2 - Hierarquia dos elementos de análise do ABC em relação aos níveis de planejamento florestal.

Fonte: ALMEIDA (1996)

considerado infrutífero para redução global de custos. Na Figura 3, a seguir, demonstra-se uma síntese da visão dos custos pelos distintos métodos de custeio.

De maneira resumida, espera-se que a metodologia do $\mathrm{ABC}$ apresente-se como oportuna, pela identificação formal de recursos inadequadamente utilizados, em atividades consideradas não agregadoras de valor ao cliente. Também KAVCIC \& ZADNIK-STIRN (1998), descrevendo a utilização do método $\mathrm{ABC}$ na empresa florestal, demonstram que esta metodologia elucida o problema de identificação dos custos fixos indispensáveis, e aqueles considerados não essenciais à performance das metas do empreendimento.

Assim, o procedimento desejado para a condução do gerenciamento baseado em atividades é observar a organização como um grupo de processos compostos por atividades críticas inter-relacionadas, viabilizadas pela análise de valor, e confrontadas pelas necessidades e expectativas do cliente. A sustentabilidade do método $\mathrm{ABC}$ dar-se-á, não pela substituição dos procedimentos contábeis tradicionais, mas pela complementariedade das informações gerenciais, visando satisfazer as necessidades de tomada de decisões estratégicas da empresa.

De acordo com NESS \& CUCUZZA (1995), deve-se evitar que o $\mathrm{ABC}$ seja um sistema de refúgio, como se sucede em algumas empresas que desenvolvem sistemas híbridos pelos analistas de sistemas, tornando-se obsoletos em pouco tempo. Por isso, afirmam os autores, é necessário não apenas aperfeiçoar o sistema de custeio, mas estruturar mudanças comportamentais e organizacionais para se atingir todos os propósitos de sucesso do modelo.

\section{Programa de Simulação da Implantação do ABC}

Dara se avaliar o método $\mathrm{ABC}$ em uma Pituação real, procurou-se uma empresa do segmento florestal na qual seria escolhida uma área ou divisão da indústria que pudesse 


\section{ESTRATÉGIA DE REDUÇÃO DE CUSTOS}

TOMADA DE DECISÃO VIA

VBC

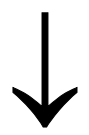

ATAQUE DIRETO AOS

RECURSOS CONSUMIDOS
TOMADA DE DECISÃO VIA

ABC

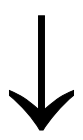

ATAQUE DIRETO AO

VALOR DAS ATIVIDADES

Figura 3 - Redução de custos: VBC X ABC.

expressar, significativamente, os diferenciais demonstrados nos distintos relatórios gerados, ou seja, o relatório tradicional adotado pela empresa em confronto ao relatório via $\mathrm{ABC}$.

A sistemática metodológica abordada estruturou-se nos conceitos de COOPER \& KAPLAN (1988), OSTRENGA et al. (1993), COGAN (1994), NAKAGAWA (1994), CHING (1995) e BRIMSON (1996) com distinções nas etapas de desenvolvimento do modelo aplicativo.

Foram realizadas reuniões iniciais com todo o pessoal envolvido, diagnosticado o sistema de custeio adotado, escolhido o setor da empresa a sofrer a investigação, desenvolvida uma sistemática metodológica de implantação do $\mathrm{ABC}$, até se determinar a apuração final dos custos de cada atividade, compatibilizados os valores encontrados por ambos os sistemas de custeio, e por fim, avaliando o grau de satisfação dos usuários das informações de custo em comparação ao sistema tradicional.

A empresa escolhida trata-se de uma das maiores empresas do ramo madeireiro nacional com atuação no oeste da região sul. Detentora de uma área de produção florestal superior a 80.000 ha e situada em quatro municípios no estado onde atua, se encontra distribuída em ramos de negócio que incluem a agricultura, a pecuária, o reflorestamento, a indústria de madeiras, e uma recente fábrica de papel e celulose.
Após o conhecimento de campo, e do desenvolvimento operacional do setor escolhido para análise na empresa, foi delineado todo o processo que compõe o nível de responsabilidade e autoridade do setor, com a estratificação do processo em atividades, que possibilitou, juntamente ao sistema já utilizado de coleta de dados, um direcionamento apropriado da apuração dos custos.

Posteriormente, a divisão de suprimento florestal foi caracterizada para se conhecer com detalhes todo o fluxo operacional de trabalho, recursos e subprodutos gerados. Foram delineadas as atividades como balizadoras do método $\mathrm{ABC}$, que fossem compatíveis com as apurações de dados já existentes na empresa. A Figura 4 demonstra o fluxograma operacional das atividades do setor.

Com essas informações, pode-se desenvolver a sistemática metodológica do $\mathrm{ABC}$, até se determinar a apuração mensal dos custos de cada atividade, e do respectivo custo por unidade.

Visando-se estabelecer uma rotina nos procedimentos recentemente implantados na metodologia proposta, e a familiarização dos envolvidos diretamente na confecção do relatório $\mathrm{ABC}$, foram estipulados três meses consecutivos de simulação para uma estruturação suficiente e adequada, no caso da elaboração do relatório gerencial para o setor escolhido. 


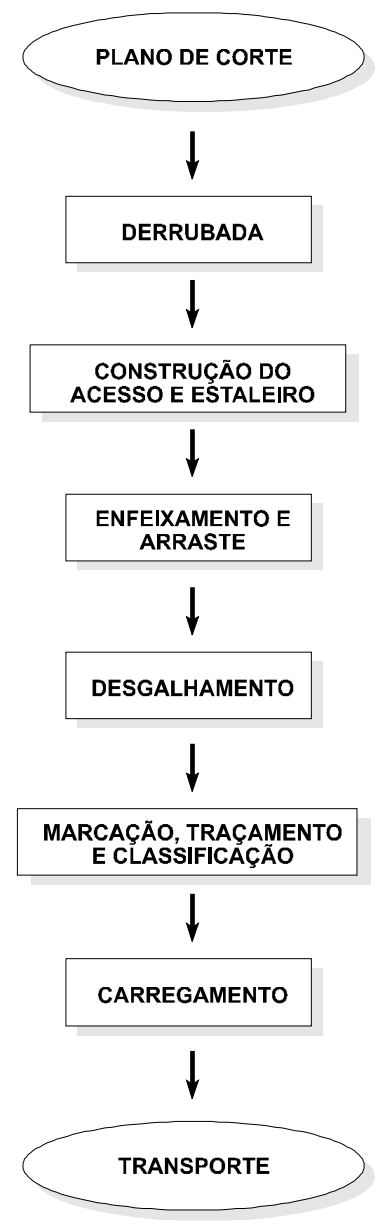

Figura 4 - Fluxograma operacional do setor de suprimento florestal.

No presente estudo, a totalização dos dados via $\mathrm{ABC}$ sempre deveria ser compatível com as informações contábeis aferidas pela sistemática tradicional, já que os valores encontrados por qualquer sistema de custeio devem habitualmente serem os mesmos, pois tratam-se de desembolsos. Este procedimento garantiu resultados em conformidade ao sistema já adotado pela empresa, inclusive com a participação direta de funcionários da contabilidade, durante todo o processo de apuração e rastreamento dos custos, sem o surgimento de possíveis controvérsias por ambas as partes envolvidas na investigação.

Tal desprendimento teve o propósito de instituir um aperfeiçoamento na distribuição e alocação por atividades de todos os custos referentes ao setor escolhido, tomando-se o cuidado de não se configurar um sistema híbrido e desprovido de comprometimento dos profissionais de contabilidade da empresa.

Finalmente, para se obter um grau de satisfação dos usuários das informações de custo, foi distribuído um formulário de avaliação, com a finalidade de formalizar as opiniões sobre a efetividade do relatório de custos via $\mathrm{ABC}$.

\section{Resultados Alcançados}




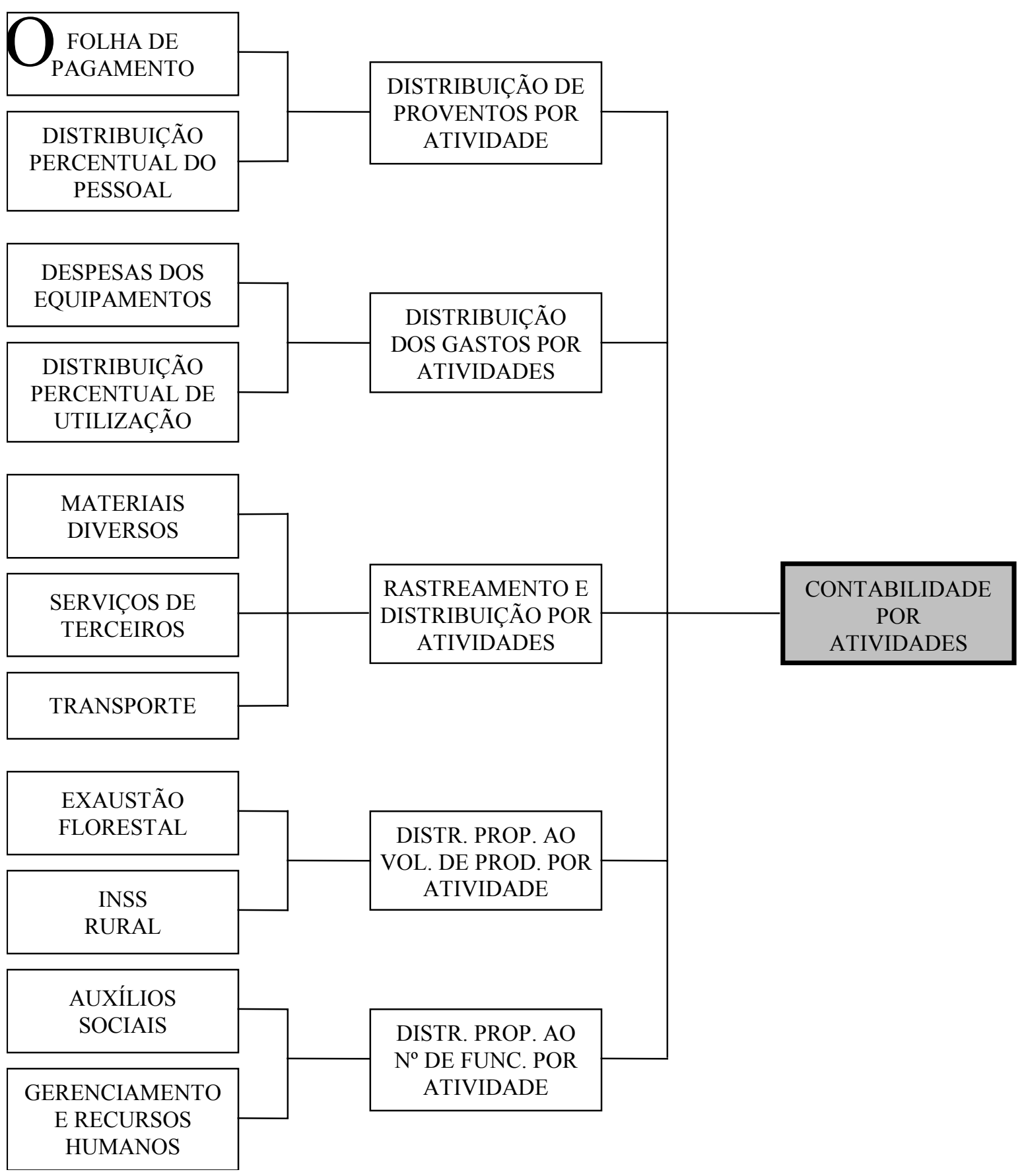

Figura 5 - Delineamento da apuração de custos via ABC.

fluxograma apresentado em seguida na Figura 5 descreve, por etapas, como foram agrupadas as bases de cálculo por centro de custo, para configuração dos direcionadores capazes de determinar a contabilidade por atividades. Após a elaboração preliminar do mapa de atividades do setor, foi realizado o rastreamento por atividade de todos os recursos diretos e indiretos correlacionados.

$\mathrm{Na}$ primeira etapa, foi montado um quadro mensal de pessoal por atividade definida, para se identificar os recursos humanos diretamente 


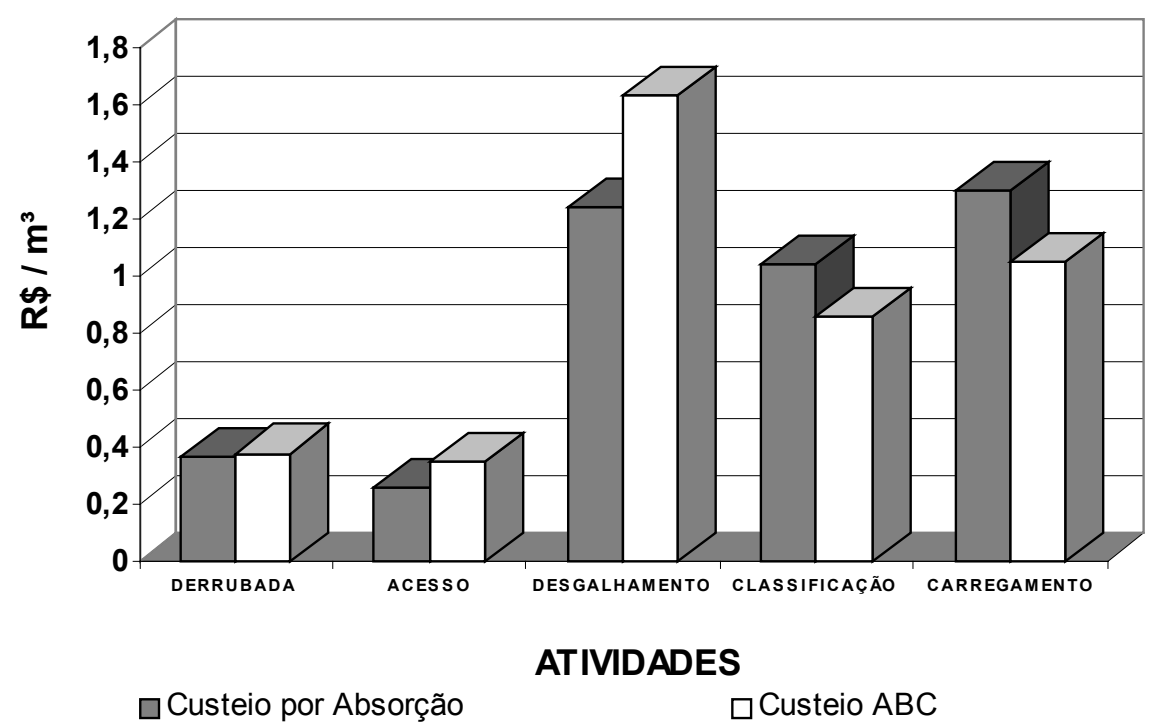

Figura 6 - Comparação dos custos unitários por atividade produtiva entre o sistema de custeio por Absorção e os sistema ABC.

envolvidos. Com relação aos funcionários que trabalhavam em mais de uma atividade, foram efetuadas investigações para se determinar a média da proporcionalidade em tempo, que se dedicavam a cada atividade.

Com o quadro de pessoal e a folha de pagamento fornecidos pelo setor administrativo, foi possível obter uma distribuição dos proventos dos funcionários no setor escolhido por atividade, alcançando-se os custos totais referentes aos salários em cada atividade definida.

Em um segundo momento, ao se considerar os equipamentos, retornou-se ao quadro de pessoal para se relacionar quais eram os equipamentos diretamente envolvidos nas atividades. Na apuração dos custos de equipamentos de utilização em múltiplas atividades, utilizou-se a média da proporcionalidade em tempo destes equipamentos por atividades. Estas medidas visaram se aproximar o mais perto possível da ideal apropriação dos custos, uma vez que é melhor estar aproximadamente certo do que precisamente errado.
Para redução de dados de pouca relevância gerencial, foram aglutinados centros de custo que possuíam alguma afinidade.

Quanto aos demais custos indiretos, foram distribuídos de acordo com a proporcionalidade produtiva, ao número de funcionários envolvidos e/ou diretamente alocados nas atividades em que foram correlacionados.

Na Figura 6, demonstra-se o confronto dos resultados referentes ao mês de abril de 1996 nos dois sistemas de custeio: o convencional (Absorção) e o ABC.

Para efeito de análise foram separadas as atividades consideradas produtivas e de suporte, até porque as grandezas eram distintas. No caso de algumas atividades, não foi possível a comparação, porque simplesmente não eram apontadas, ou se confundiam com as demais. $\mathrm{Na}$ Figura 7, demonstra-se o confronto destas atividades consideradas de suporte.

Conforme demonstrado, nota-se visualmente os diferenciais obtidos pelas duas metodologias de custeio. Evidencia-se que, possivelmente, os administradores florestais devem estar direcio- 


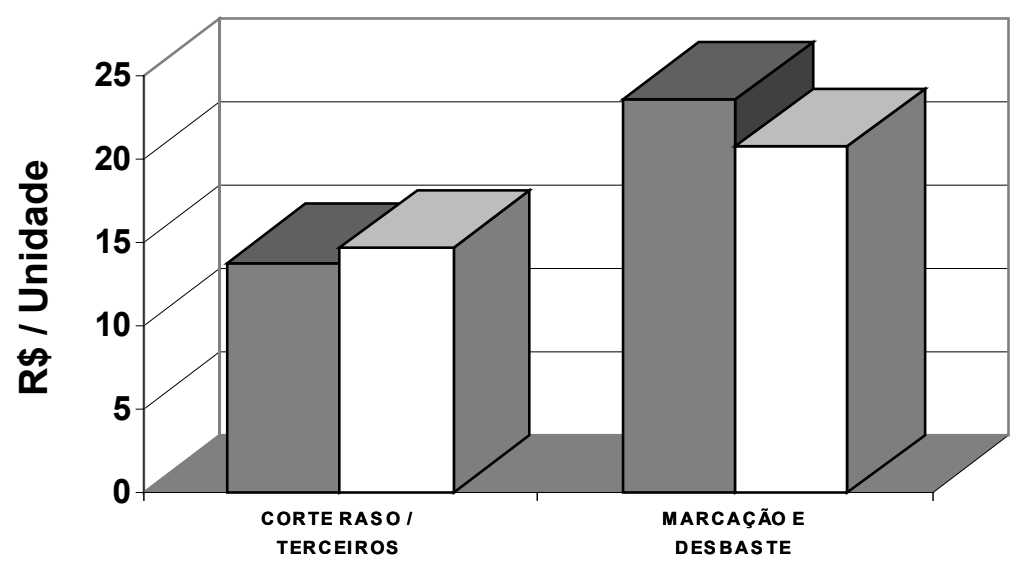

ATIVIDADES

Custeio por Absorção

$\square$ Custeio $A B C$

Figura 7 - Comparação dos custos unitários por atividade de suporte entre o sistema de custeio por Absorção e o sistema ABC.

nando suas decisões de forma equivocada pela ausência de precisão da sistemática contábil utilizada pela empresa.

No caso da atividade de desgalhamento em que o diferencial supera os $30 \%$, observou-se que além das imprecisões incorridas pela sistemática convencional, havia discrepâncias entre a realidade operacional e os apontamentos contábeis que ainda não tinham sido atualizados, em termos dos recursos fisicamente utilizados para o desenvolvimento da atividade. Pode parecer que o sistema contábil da empresa fosse extremamente precário, ou que necessitasse de aperfeiçoamentos, mas é o que se sucede na maioria das empresas do setor florestal, e mesmo em outros setores, cujos sistemas convencionais nunca foram questionados, principalmente pelos seus clientes operacionais.

Grande parte das explicações sobre os diferenciais referem-se ao custeio da mão-de-obra. No procedimento adotado pela empresa, estes custos são considerados como apenas um valor médio resultante da somatória de todos os salários dos funcionários do setor, que dividido pelo total de horas gastas por esses funcionários, conferem um valor apropriado, proporcional- mente, ao número de horas gastas por processo, referentes à mão-de-obra.

Com certeza, naquelas atividades que tiverem um custo/hora preciso da mão-de-obra, significativamente mais baixo ou mais elevado (isto é, distante da média) em comparação ao custo médio considerado pela sistemática tradicional, existirão distorções relevantes na contabilidade dos custos salariais.

Estas resultantes, particularmente, já distinguem de maneira integral a metodologia dos dois sistemas de custeio, e contribuem para imprecisão das informações convencionais de custeio, promovendo discrepâncias nas tomadas de decisões estratégicas pela empresa.

\section{Discussão}

A forma de rateio simplista, calcada na apropriação da mão-de-obra direta, e no material diretamente envolvido fornecido pelo sistema por absorção encontrado na empresa, resguardado o fato do sistema adotado não estar perfeitamente atualizado, como ocorre na grande maioria das empresas do ramo, demonstrou-se 
imprecisa e, conseqüentemente, ineficaz para auxílio na tomada de decisões gerenciais.

De maneira antagônica, o ABC destaca-se pelo rastreamento e distribuição dos custos indiretos de fabricação, oferecendo ao gerenciamento melhores oportunidades de identificação e monitoramento dos custos unitários dos produtos e/ou serviços, otimizando a eficiência administrativa, e minimizando erros no momento de se optar pela interrupção ou troca do processo fabril, no fornecimento de descontos, no investimento em equipamentos, na ampliação de setores da empresa, etc.

Da mesma forma demonstrada no setor escolhido, pode ser fornecido a cada gerente de divisão um subsistema do $\mathrm{ABC}$ que atenda suas necessidades particulares com relatórios precisos, no momento oportuno e atualizado. Estas características foram ratificadas pelos usuários das informações de custo, pelas avaliações realizadas após a geração do relatório ABC. Para exemplificar o posicionamento de um dos usuários, prescreve-se um trecho do relato do Gerente Florestal: “... a facilidade de análise dos itens componentes proporciona um melhor gerenciamento dos custos".

Para obtenção de sucesso no programa, recomenda-se a implantação do sistema de maneira gradativa, e não imposto com os mesmos níveis de detalhamento por todos os setores da empresa, até porque, possibilita os ajustes apropriados a cada caso, diferindo significativamente, da grande maioria dos pacotes ofertados por empresas de consultoria.
Ao se segregar os processos em atividades, buscou-se um nível de detalhamento compatível, tanto ao sistema de apuração econômico e viável dos custos, como ao entendimento por parte dos diversos níveis de funcionários, daquelas atividades responsáveis pelos produtos e/ou serviços gerados no setor escolhido. No entanto, este detalhamento, composto da subdivisão dos processos, seja em macro ou micro-atividades, dependerá exclusivamente, da estratégia adotada, considerando a variação nos custos de implantação e operacionalização do ABC.

Devido ao êxito alcançado no programa descrito, conclui-se que a metodologia proposta, guardada suas proporções e ajustes necessários, permite a expansão por toda a empresa.

Outro benefício gerado pela utilização do $\mathrm{ABC}$, é que ele proporciona a identificação do nível de agregação de valor das atividades aos produtos/serviços resultantes. Neste ponto, a empresa pode fomentar programas efetivos de redução de custos, principalmente naqueles processos considerados vitais, protelando o foco nos processos triviais (redução de fotocópias, cafezinho, despesas de viagens, etc.) devido a baixa representatividade ao desenvolvimento do negócio.

Mediante a metodologia proposta, não só indústrias do setor florestal como também outros setores de negócio, poderão se beneficiar da capacidade analítica do $\mathrm{ABC}$, pelas medidas de desempenho e seus custos unitários, as quais fornecem subsídios relevantes aos administradores na tomada de decisões estratégicas, táticas e operacionais.

\section{Referências Bibliográficas}

ALMEIDA, A.R.C.: "Reduzindo desperdícios florestais." Silvicultura, São Paulo, no 58, p.42-43, nov./dez., 1994.

—_: "Reengenharia florestal." Revista da Madeira. Caxias do Sul. no 21, p.9, mar./abr., 1995.
-: Método de custeio baseado em atividades no setor florestal. Curitiba, Dissertação (Mestrado em Ciências Florestais), Setor de Ciências Agrárias, Universidade Federal do Paraná, Curitiba, 1996.

BERLINER, C. \& BRIMSON, J.A.: Gerenciamento de custos em industrias avançadas. São Paulo, Ed. T. A. Queiroz, 1992. 
BREPOHL, D.: Custos em empreendimentos florestais. Curitiba, Ed. FUPEF, série técnica $n^{\circ} 4$, nov., 1980.

BRIMSON, J.A.: Contabilidade por atividades. São Paulo, Ed. Atlas, 1996.

BRUNT, P.D.: Como reduzir custos. São Paulo, Ed. Nobel, 1992.

CHING, H.Y.: Gestão baseada em custeio por atividades. São Paulo, Ed. Atlas, 1995.

COGAN, S.: Activity - based costing (ABC). São Paulo, Ed. Pioneira, 1994.

COOPER, R. \& KAPLAN, R.S.: "Measure cost right: make the right decisions." Harvard Business Review. Boston, sep/out, 1988, p.96-103.

DEVELIN, N.: Processo de aperfeiçoamento contínuo. São Paulo, Ed. IMAM, 1995.

DRUCKER, P.F.: Administrando para o futuro. São Paulo, Ed. Pioneira, 1992.

GANTZEL, G. \& ALORA, V.: Revolução nos custos: os métodos ABC e UP e a gestão estratégica de custos como ferramenta para competitividade. Salvador, Ed. Casa da Qualidade, 1996.

GOLDRATT, E.M.: A síndrome do palheiro. São Paulo, Ed. Educator, 1992.

HELLINGA, M.: "El modelo de Ceasa y su rentabilidad." In: Congreso Forestal Español (1993: Lourizán). Anais. Lourizán: 1993, v.4, p.399-403.

JOHNSTON, D.R.; GRAYSON, A.J. \& BRADLEY,

R.T.: Planeamento florestal. Lisboa, Ed. Fundação Calouste Gulbenkian, 1977.
NAKAGAWA, M.: ABC. Custeio baseado em atividades. São Paulo, Ed. Atlas, 1994.

KAVCIC, S. \& ZADNIK-STIRN, L.: “Acitivity-based costing in forestry." In: Accounting and Managerial Economics for an EnvironmentallyFriendly (1997:Nancy). Anais. Versailles: INRAEditions, 1998, p.87-96.

NESS, J.A. \& CUCUZZA, T.G.: "Tapping the full potential of ABC." Harvard Business Review. Boston, July/Agu, 1995, p.130-138.

OSTRENGA, M.R.; OZAN, T.R.; McILHATTAN, R.D. \& HARDWOOD, M.D.: Guia da Ernst \& Young para gestão total dos custos. $12^{\mathrm{a}}$ ed., Rio de Janeiro, Ed. Record, 1993.

OPENSHAW, K.: Cost and financial acoounting in forestry. Oxford, Ed. Pergamon Press, 1980.

SÁNCHEZ, Z.E.: "El manejo del costo en la economia de la industria forestal maderable. In : Reunion Nacional Sobre Economia Forestal." (1985: Guadalajara). Anais. México: Secretaria de Agricultura y Recursos Hidraulicos, Publicação Especial, $n^{\circ} 47$, p.285-291.

SHANK. J.K. \& GOVINDARAJAN, V.: Gestão estratégica de custos. Rio de Janeiro, Ed. Campus, 1995.

SLACK, N.: Vantagem competitiva em manufatura. São Paulo, Ed. Atlas, 1993.

SPEIDEL, G.: Economia florestal. Curitiba, Ed. UFPR, 1966.

TAYLOR, F.W.: Princípios de administração científica. $7^{\text {a }}$ ed., São Paulo, Ed. Atlas, 1978.

\title{
FOREST MANAGEMENT COSTS: A CASE STUDY UTILIZING ACTIVITY-BASED COSTING
}

\begin{abstract}
In the current view of globalized industrialization, it has become fundamental to manage essential costs effectively. Conventional programs for reducing costs, do no consider the value agregation grade of routine activities because of the distortion of current accounting systems. This study, presents the main reasons for the lack of relevance of the cost information, commenting on the problem of the reduction of forest waste and its consequences. Using a case study in a company from the forest sector, a simulation of Activity Based Costing $(A B C)$ is demonstrated in a determined area of the
\end{abstract}


company it is concluded that the adoption of a more refined cost system, such as the ABC, should be included in programs, that seek to increase the competitiveness of the forest sector.

Key words: cost management, forest economics, activity-based costing. 